\title{
Uso das redes sociais, imagem corporal e influência da mídia em acadêmicos dos cursos de educação física
}

\author{
Mariany Silva Santos ${ }^{1}$ \\ Vivianne Oliveira Gonçalves ${ }^{2}$
}

Resumo: A aparência corporal está se tornando cada vez mais importante para nossa sociedade e a forma como é utilizada pela mídia é preocupante, encarada como produto e sendo alvo da instituição de padrões de corpo a serem seguidos. As redes sociais são um instrumento atual usado pela mídia para difundir informações. O padrão de corpo disseminado, através das redes sociais é, na maioria das vezes, inalcançável para a população, causando insatisfação com a imagem corporal. A partir de tais observações, surge este trabalho que teve por base de pesquisa a coleta de informações. A pesquisa foi realizada com 112 estudantes dos cursos de Educação Física, licenciatura e bacharelado, sendo de todos os períodos, ambos os sexos e sem idade definida para a participação. Eles responderam a três questionários, o primeiro sociodemográfico; o segundo sobre o uso das redes sociais, elaborado pela pesquisadora, com perguntas referentes à frequência, tempo e conteúdo de uso dessas ferramentas. $\mathrm{O}$ terceiro é o Sociocultural Attitudes Towards Appearance Questionnaire-3 (SATAQ-3), validado para o Brasil por Amaral (2011). Os dados foram organizados e analisados por meio do programa SPSS, versão 2.0 para Windows. Foi adotado o nível de significância estatística $p<0,05$ e realizada uma análise descritiva dos dados. Como principais resultados da pesquisa, 99,1\% da amostra $(48,2 \%$ do sexo masculino e 50,9\% do sexo feminino) afirma fazer uso das redes sociais e apenas uma pessoa do sexo masculino $(0,9 \%)$ diz não utilizar. Sobre as redes sociais mais usadas em função do sexo, as mais mencionadas são: whatsApp 96,4\%, instagram 79,5\% e facebook 75,9\%. Em relação aos fatores SATAQ-3, os que obtiveram maior pontuação foram os fatores 1 (internalização geral dos padrões estabelecidos), seguido do fator 4 (mídia como fonte de informações sobre aparência) para ambos os sexos, o que indica que esses fatores possuem maior influência sobre as participantes. Podemos verificar que há uma influência por parte da mídia, em ambos os sexos, verificamos que as diferenças são mínimas, o que nos leva a concluir que a influência da mídia ocorre de forma igualitária em ambos os sexos.

Palavras - Chave: Imagem corporal. Mídia. Redes sociais.

\footnotetext{
${ }^{1}$ Mestranda em Educação (PPGE/UFG/Regional Jataí), formada no curso de educação física em licenciatura na Universidade Federal de Góias - Regional Jataí. Membra do Grupo de estudos: Pedagogia Histórico Crítica (PHC/Uni-Oeste). Bolsista do Programa Institucional de Bolsa de Iniciação à Docência - PIBID no subprojeto de Educação Física, no período de 05/2016 a 09/2016 e subprojeto interdisciplinar no período de 2017 a 2018; membro do Gestos Grupo Ginástico - GGG, dos cursos de Educação Física licenciatura e bacharelado da referida Universidade; monitora voluntária do Núcleo de Práticas Corporais - NPC, no ano de 2016/1. E-mail: mar_e_any@hotmail.com

${ }^{2}$ Licenciada em Educação Física pela Universidade Federal de Goiás (1998), Mestre em Educação Física pela Universidade Estadual de Campinas (2002) e Doutorado em Ciências da Atividade Física e do Esporte (2012) pela Universidad de Castilla La Mancha (UCLM-Espanha). Atualmente, é docente dos cursos de Educação Física da Universidade Federal de Jataí e do Programa de Pós-Graduação (Mestrado em Educação) da UFJ. Temas de pesquisa: Imagem Corporal, Formação Humana na perspectiva da Psicologia Sócio Histórica; Relações de Gênero; Corpo, Sexualidades e Educação; Produção de Subjetividades, Gênero e Espaços Educativos (pedagogia escolar e pedagogia cultural); Políticas Sociais, Educação e Gênero. Atua como pesquisadora nos Grupos de Pesquisa Multidisciplinaridade e Saúde, e NESEC - Núcleo de Estudos Sociedade, Educação e Cultura, ambos da UFJ-. E-mail: vivianefef@gmail.com
} 


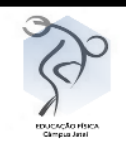

\title{
Use of social networks, body image and media influence in academics of the physical education course
}

\begin{abstract}
Body appearance is becoming more important everyday to our society, and it's alarming the way it's been used by the media, seen as a product and being a target of the institutionalization of the body standards to be followed. The social-network is a current instrument used to disseminate information. The body standard disseminated through the social-network is unattainable for most of the population, causing dissatisfaction with the body image. This work came from this observations that collected information as a research baseline. The research was conducted with 112 students of Physical Education - bachelor's and graduation's, from all periods, both sexes and no limit of age as a condition for the participation. They answered 3 surveys; the first was sociodemographic, the second was about the use of the social networks, developed by the researcher, with questions about the frequency, time and content of the use of this tools. The third is the Sociocultural Attitudes Towards Appearance Questionnaire - 3 (SATAQ-3), validated to Brazil by Amaral (2011). The data was organized and analyzed through the SPSS program, version 2.0 for Windows. The level of statistic definition adopted was $\mathrm{p}<0,05$ and a descriptive analysis of the data was realized. As the main results of the research $99,1 \%$ of the sample $(48,2 \%$ of the male gender and $50,9 \%$ of the female gender) affirm to use the social networks and just one person of the male gender $(0,9 \%)$ said he doesn't make use of it. Regarding the social networks that are more used in function of sex, the most mentioned were: WhatsApp (96,4\%), Instagram (79,5\%), Facebook (75,9\%). Regarding the SATAQ-3 factors, the ones with higher scores were the factors: 1 (general internalization of the stablished patterns) followed by the factor 4 (mídia as the source of information about physical appearance for both genders which indicates that this factorhave bigger influence over the participants. We can verify that there is an influence from the media over both genders, we verified that the differences are minimum, which lead us to conclude that the influence of the mídia happens equally on both genders.
\end{abstract}

Keywords: Body Image. Media. Social Network.

\section{INTRODUÇÃO}

Essa pesquisa se trata, sobretudo, acerca da imagem corporal e os modelos corporais difundidos na mídia e nas redes sociais e de como vemos nossa imagem corporal a partir dessas influências.

O objetivo geral dessa pesquisa foi investigar a relação entre o uso das redes sociais, a influência da mídia e a imagem corporal de acadêmicos dos cursos de Educação Física, de ambos os sexos. Como objetivos específicos, buscamos: analisar o uso das redes sociais por universitários; investigar a influência da mídia na imagem corporal dos sujeitos; averiguar se houve uma relação do uso das redes sociais com a influência da mídia sobre a 


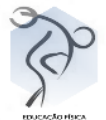

imagem corporal; verificar se existe influência por parte da mídia em ambos os sexos de forma igualitária.

Andrieu (2006) acredita que o corpo é resultado de um programa genético e se desenvolve de forma maior ou menor com influência de sua cultura; e é resultado de uma construção simbólica que envolve tanto as percepções quanto as representações de formas individuais e coletivas. Já Foucault (1987) diz que o corpo é um difusor de comunicação da mídia; é a expressão corporal com sentido cultural e que é transformada em mercadoria.

Por vermos que na atualidade o corpo está sendo tratado como um produto, observamos que vem sendo difundido um padrão de corpo tanto para o sexo feminino como para o masculino. A mídia utiliza vários meios para essa difusão e nisso as redes sociais têm sido um grande percussor dessa ideia de corpo perfeito e modelo de corpo ideal para ambos os sexos.

Giddens (1998) declara que os corpos são apontados como produto, analisados pela eficácia e qualidade, sendo educados, ordenados, catalogados e rotulados. Esse modelo de corpo aparece também nas redes sociais, sendo esta considerada atualmente como uma difusora desse corpo ideal, sendo o local onde, muitas vezes, esses modelos (de ambos os sexos) são reconhecidos e atribuídos a eles o critério de corpo saudável, em forma, ou seja, o modelo de corpo ideal e satisfatório.

Tavares e Brasileiro (2003) defendem que a mídia também define modelos de beleza e padrões corporais a serem propagados dentro do comércio de padrões de beleza, imitados pela sociedade, tanto no modo de viver como no modo de ver o corpo.

É recorrente em nossa geração essa atenção ao corpo. Seja na alimentação, em exercício, intervenção cirúrgica, dentre outras práticas que vêm se tornando comuns para pessoas que têm como objetivo a busca desse corpo considerado ideal. Da mesma forma, as redes sociais têm sido referência para os modelos corporais e os cuidados relacionados ao corpo. É de suma importância para a área da saúde estudar esse tema, assim como a relação entre imagem de corpo e influência da mídia para universitários.

Esse artigo foi estruturado em três capítulos. No primeiro - revisão da literatura são abordados os conceitos e formação da imagem corporal, a insatisfação e a influência da mídia e das redes sociais na percepção do corpo. O segundo capítulo trata da metodologia 


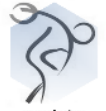

adotada para a realização da pesquisa. No terceiro capítulo se apresenta os resultados da pesquisa de campo e discute-se sobre os dados encontrados. Por fim, são apresentadas as considerações finais e referências que fundamentaram o estudo.

\section{IMAGEM CORPORAL}

\subsection{Conceitos e formação}

Gonçalves; Campana e Tavares (2012) definem a imagem corporal como uma reprodução elaborada na mente do nosso próprio corpo. Essa imagem do corpo foi adquirida por meio de componentes cognitivos, emocionais e comportamentais, todos em uma junção com um mesmo grau de importância

Schilder (1999, p.07) nos define a imagem corporal como sendo "a figuração de nosso corpo formada em nossa mente, ou seja, o modo como ele se apresenta para nós".

Essa imagem está constituída por três componentes, esses componentes sofrem variações com o tempo. Sendo assim, ela não é algo preciso, sofre variações ao longo do tempo e é percebida de diferentes formas desde o nascimento até o envelhecimento. "Temos, portanto, um número quase ilimitado de imagens corporais” Schilder (1999, p.73).

Sendo assim, a imagem de corpo está sempre em processo de mudança, em muitos casos por ser adquirida através da convivência com outras pessoas, em determinada cultura, com seus valores, crenças, sendo atualmente muito influenciada pela mídia, já que esta se encontra cada vez mais presente em nossas vidas.

De acordo com Schilder (1999), a imagem corporal é formada por três estruturas, que se relacionam entre si, sendo elas: a fisiológica, a libidinal e a social. A estrutura fisiológica seria a responsável pelas organizações anatomofisiológicas (sistema ósseo, muscular, nervoso e emocional), incluídas as contribuições genéticas e as modificações sofridas por funções somáticas. Já a estrutura libidinal, Schilder (1999) considera como as experiências, vivenciadas nos relacionamentos, ao longo da vida, desde a gestação. A estrutura sociológica se refere aos intercâmbios pessoais e à aprendizagem dos valores culturais e sociais. 
Os aspectos fisiológicos e libidinais acontecem no nosso corpo a todo instante e sempre estão em processo de transformação. Construímos em nossa mente metáforas relacionando o "físico, o fisiológico e o biológico" e nessas metáforas criamos ideias de imagens corporais mais básicas como: o bonito e o feio, o ser "superior" e o ser "inferior.

Os aspectos sociais, por outro lado, têm vários pontos que são importantes e ajudam a construir de forma fundamental a imagem corporal, ou seja, como nós interagirmos faz com que criemos de forma mais fácil imagens corporais, sendo uma forma de reciprocidade. Nesse sentido, Barros (2001) afirma que o processo social é importante, porque se relaciona com as experiências adquiridas ao longo da vida, principalmente na fase de formação da imagem de corpo, desde a gestação.

\section{2 (In)satisfação e a influência da mídia}

A insatisfação e satisfação corporal tem como aspecto principal a percepção do indivíduo sobre a sua própria imagem corporal.

\footnotetext{
A satisfação corporal nada mais é do que o indivíduo estar bem consigo mesmo, ver sua imagem refletida no espelho ou ter a percepção de seu corpo e gostar do que percebe. Já a insatisfação corporal é o inverso, o que acarreta sentimentos e pensamentos negativos sobre a própria aparência, influindo no bem-estar emocional e na qualidade de vida do indivíduo (PIVA, 2013 p. 22).
}

Correia (2006) defende que a satisfação da imagem corporal está relacionada a pensamentos positivos, com o fato de gostar da sua imagem e de como ela é refletida. Atualmente, também tem sido relatada a insatisfação corporal por não ter conseguido moldar o corpo de acordo com o que é influenciado pela mídia e as redes sociais. A insatisfação está relacionada com o não gostar de sua própria aparência física, muitas vezes por não conseguir ter as medidas "ideais", estar frustrado com a sua imagem corporal atual e não conseguir o corpo tão desejado, mesmo quando há uma busca incessante por ele.

Para tentar entender um pouco mais sobre mídias sociais e redes sociais, é necessário traçar uma breve explicação sobre o conceito de rede social. Alguns autores acreditam que mídias sociais e redes sociais fazem parte de um mesmo sistema tendo assim um mesmo significado. 
A palavra mídia é derivada do latim "media", plural de "medium" e que tem como significado as palavras "meio" ou "forma". A mesma palavra é derivada de outros vocabulários como o inglês "media", que no Brasil é mais utilizado através da palavra "mídia", derivada da pronuncia inglesa. Baseando-se no significado da palavra, começamos a definir melhor o que vêm a ser mídia (DUTRA, 2011, p.1).

As mídias sociais para alguns autores, seriam como uma subdivisão de mídia, tendo diversos meios que estariam todos nesse mesmo conceito como: e-mail, blogs, sites e aplicativos de redes sociais (Instagram, facebook, WhatsApp).

Já para Primo, o conceito de mídias sociais engloba tudo, já que são mantidas na sociedade.

Os homens, ora, são os criadores e mantenedores das mídias. Tanto rádio quanto $\mathrm{TV}$, tanto um jornal quanto um blog seriam, pois, sociais. Na esteira deste raciocínio, o termo "mídias sociais" despir-se-ia de qualquer relevância, já que não aparta nenhuma distinção: se todas mídias são sociais, nenhuma instância ficaria de fora (PRIMO, 2012 p. 619).

O grande impacto da mídia na imagem corporal seria a forma de como as pessoas enxergam sua imagem corporal em comparação com os modelos corporais disseminados pela mídia e de como essa comparação gera ou não uma insatisfação corporal.

Dessa forma, Tavares e Brasileiro (2003) nos mostra que este tipo de corpo que é difundido pela mídia, também estipula padrões de corpos a serem seguidos, tanto no "como viver", como na forma “de ver" o corpo.

Com essa difusão de um corpo ideal, a imagem corporal se transformou em mercadoria, como Foucault (1987) já havia retratado. Segundo Vieira e Bosi (2013, p.849), "trata-se de uma exploração econômica do corpo pela via da saúde, do mundo da malhação, da confecção do corpo".

A mulher perfeita existe e mora nas representações midiáticas. Ela é bonita, inteligente, divertida, engraçada, mãe amorosa e amante voraz: e, além de todas essas vantagens, come pouco e tem, por causa disso e da malhação constante, um corpo escultural, perfeito. Essa mulher existe na tevê, nas revistas, nos jornais e, hoje, especialmente existe e se alimenta das redes digitais, que se tornaram um ponto de grande inflexão do culto à magreza e ao corpo ideal (JACOB, 2014, p.90). 
Podemos notar que essa difusão e propagação da mídia por esse corpo ideal é a grande jogada para conseguir influenciar a população, pelo interesse próprio, transformando o corpo em mercadoria. Nosso corpo é submetido como mercadoria desde a descoberta do Brasil, quando escravizaram nossos ancestrais. Não com o mesmo objetivo, atualmente nosso corpo se tornou um objeto de faturamento em vários aspectos como: produtos estéticos, dietas de "emagrecimento", produtos da linha fitness e intervenções cirúrgicas, todos buscando um mesmo objetivo, o corpo perfeito.

Sobre a mídia, a imagem corporal e a Educação Física comenta-se que:

a mídia está inserida no campo da educação física e exerce grande influência, talvez o de maior evidência seja o que se refere ao discurso sobre os benefícios do exercício físico para a promoção e manutenção da saúde, aproveitando-se da possibilidade de mercadorização que podem advir com esta simbólica venda de saúde e melhor qualidade de vida por meio do exercício físico (PATROCÍNIO, 2012 p.18-19).

Com isso podemos crer no que Patrocínio (2012) traz e notar que a mídia está atuando também na educação física com um discurso manipulador sobre saúde, qualidade de vida e até mesmo melhorar o aspecto físico por meio do exercício.

\section{METODOLOGIA}

\subsection{Caracterização da pesquisa}

Trata-se de uma pesquisa quantitativa por conter aspectos de quantificação, neutralidade do pesquisador, sendo indispensável a mensuração de dados de acordo com os resultados obtidos na pesquisa.

Um dos procedimentos utilizados na pesquisa foi o descritivo, de cunho também positivista, que tem sua grande característica de descrever os objetos e/ou sujeitos de pesquisa e analisar os resultados obtidos. Outros dois procedimentos que foram utilizados na pesquisa são: pesquisa bibliográfica e pesquisa de campo.

\subsection{Amostra}

A pesquisa foi realizada na Universidade Federal de Goiás, na Regional Jataí. Os participantes foram os alunos dos cursos de Educação Física (Licenciatura e Bacharelado) de todos os períodos, totalizando 112 alunos. 
Ressalta-se que a pesquisa foi realizada com alunos dos cursos de educação física com total de 128 alunos, mas foram descartados 16 questionários por falta de respostas, totalizando 112 questionários respondidos.

\subsection{Instrumentos de coleta de dados}

Foram utilizados três questionários:

1) Questionário sociodemográfico, elaborado pela pesquisadora, com perguntas para distinguir alguns dados pessoais e sobre a formação acadêmica de cada um.

2) Questionário com perguntas sobre o uso de redes sociais, elaborado pela pesquisadora, com perguntas referentes à frequência e tempo de uso das redes sociais, além de questões a respeito dos conteúdos mais buscados nas redes sociais, referentes ao corpo.

3) Questionário Sociocultural Attitudes Towards Appearance Questionnaire-3 (SATAQ-3). A versão original do SATAQ foi desenvolvida por Thompson et al. (2004) e validado para o Brasil por Amaral (2011), com algumas perguntas voltadas mais à população feminina. Nesse questionário constam trinta itens que avaliam a influência da mídia na percepção corporal das pessoas. Esses itens são divididos em quatro fatores: 1) Internalização geral dos padrões estabelecidos (questões $3,4,7,8,11,12,15,16,27$, que buscam informações relacionadas à beleza veiculadas pela mídia); 2) Internalização atlética (questões 19, 20, 23, 24, 30, que se referem à influência da visão de um corpo atlético no investimento da aparência); 3) Pressão sobre o corpo perfeito e o quanto a mídia influencia o indivíduo a persegui-lo (questões 2, 6, 10, 14, 18, 22, 26); 4) Mídia como fonte de informações sobre aparência (questões 1, 5, 9, 13, $17,21,25,28,29$, que visam verificar o quanto os canais de mídia são influenciadores como fontes de informações sobre ser atraente. O resultado dos escores é dado pela soma das respostas em cada fator. Quanto maior o escore, maior é a internalização das mensagens da mídia específicas do fator.

\subsection{Tratamento dos dados}

Os dados foram organizados e analisados por meio do programa Statistical Package for the Social Sciences (SPSS), versão 2.0 para Windows. O nível de significância adotado foi de $\mathrm{p}<0,05$. A distribuição dos dados foi verificada por meio do teste de Kolmogorov-Smirnov e foi encontrada distribuição normal. Foi realizada análise descritiva, 


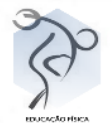

detalhada por números absolutos e porcentagem para dados categóricos. Já os dados quantitativos foram apresentados pela média, mínimo, máximo e desvio-padrão.

Para analisar as perguntas sobre mídias sociais referente ao questionário Atitudes Socioculturais em Relação ao Corpo/Imagem Corporal e a Mídia, foi calculado o escore total, por meio da somatória das respostas, sendo que quanto maior a pontuação, maior a influência da mídia.

A correlação de Pearson foi calculada para determinar o grau de associação entre a pontuação nos fatores e no escore total do SATAQ-3, IMC e variáveis referentes às redes sociais. O coeficiente da correlação de Pearson mede o grau de associação ou relação linear entre duas variáveis, ou seja, quando uma mudança em uma variável é a associada em uma mudança proporcional em outra variável. Esse coeficiente assume valores entre -1 e 1 . Os resultados foram interpretados da seguinte forma:

- Correlação muito forte: $\mathrm{r}(0,90-100)$

- Correlação forte: $\mathrm{r}(0,75-0,90)$

- Correlação moderada: $\mathrm{r}(0,50-0,75)$

- Correlação fraca: r $(0,25-0,50)$.

\section{RESULTADOS E DISCUSSÃO}

Os primeiros dados a seguir serão sobre a categorização da amostra. A pesquisa foi realizada com alunos de todos os períodos dos cursos de educação física: licenciatura e bacharelado. Responderam ao questionário 112 alunos, sendo 49,1\% alunos do sexo masculino e $50,9 \%$ do sexo feminino.

A grande maioria dos sujeitos são solteiros, sendo $42,0 \%$ do sexo masculino e $39,3 \%$ do sexo feminino.

O gráfico 1 mostra a porcentagem de respostas obtidas por alunos do bacharelado e licenciatura. Como podemos notar em ambos os sexos, a porcentagem maior é dos estudantes do curso de bacharelado, pelo fato de concentrar maior número de alunos em todos os períodos. 


\section{REFLETIONIS}

REVISTA ELETRÔNICA DE GRADUAÇÃO E PÓS-GRADUAÇÃO EM EDUCAÇÃO

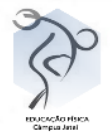

Gráfico 1. Percentual de alunos de cada curso em função do sexo.

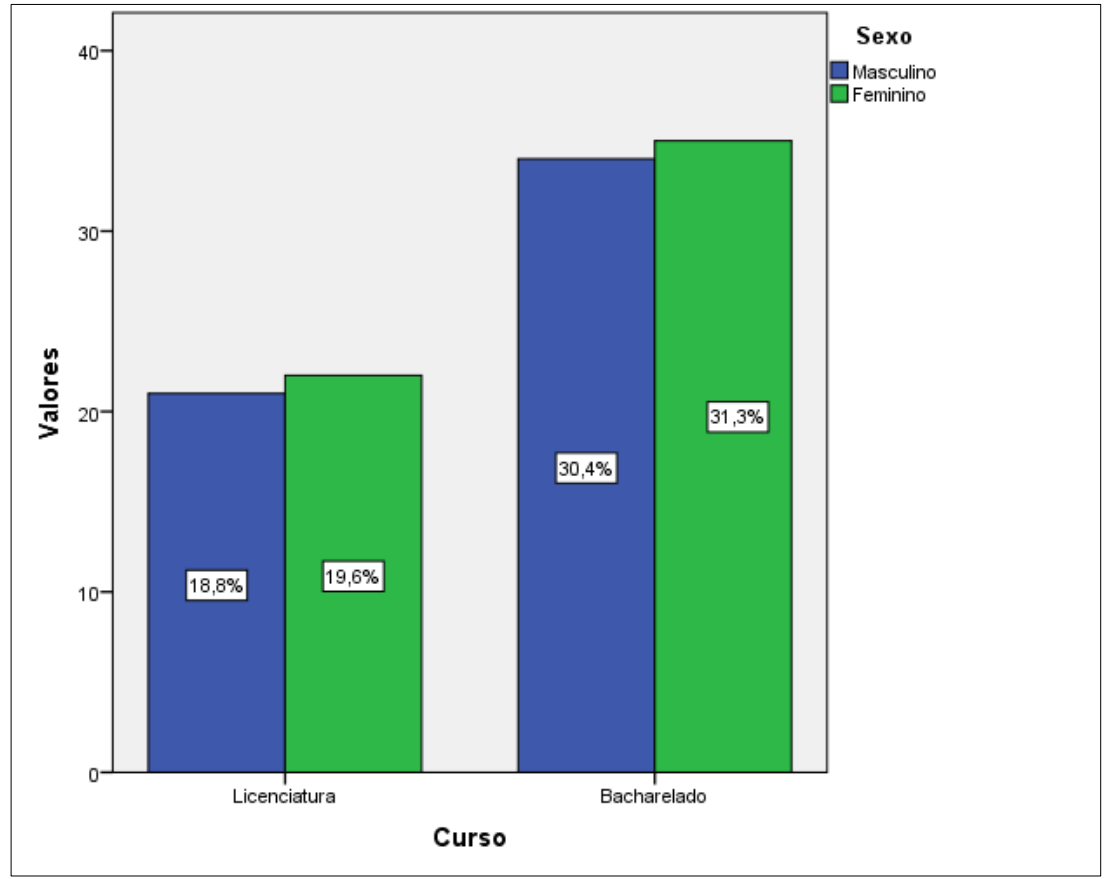

Fonte: Questionário sociodemográfico (SANTOS, 2018)

A tabela 1 mostra as características antropométricas e de idade da amostra do estudo. A idade média do sexo masculino é de 24,51 e a do sexo feminino é de 23,49 , sendo que a média de idade teve uma variação de 1 ponto entre os sexos. Já a média do IMC apresenta uma alteração maior que de um ponto entre os sexos, sendo 25,06 no sexo masculino e 23,53 no sexo feminino.

Tabela 1. Características antropométricas e de idade da amostra em função do sexo

\begin{tabular}{lrrrrrrrr}
\hline & \multicolumn{3}{c}{ masculino } & \multicolumn{7}{c}{ feminino } \\
\cline { 2 - 8 } & Média & Mínimo & Máximo & \multicolumn{1}{c}{$\begin{array}{c}\text { Desvio } \\
\text { padrão }\end{array}$} & Média & Mínimo & Máximo & $\begin{array}{r}\text { Desvio } \\
\text { Padrão }\end{array}$ \\
\hline idade & 24,51 & 18,00 & 66,00 & 7,50 & 23,49 & 18,00 & 52,00 & 5,65 \\
peso & 77,35 & 55,00 & 105,00 & 11,25 & 62,95 & 40,00 & 114,43 & 14,12 \\
altura & 175,73 & 157,00 & 193,00 & 7,42 & 163,33 & 150,00 & 180,00 & 6,49 \\
IMC & 25,06 & 18,17 & 32,37 & 3,29 & 23,53 & 16,49 & 45,84 & 4,86 \\
\hline \multicolumn{7}{c}{ Fonte: Questionário sociodemográfico (SANTOS, 2018) }
\end{tabular}




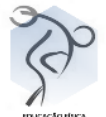

\subsection{Uso das redes sociais e SATAQ-3}

Com relação ao uso de redes sociais, $99,1 \%$ da amostra (48,2\% do sexo masculino e 50,9\% do sexo feminino) afirmam fazer uso das redes sociais e apenas uma pessoa do sexo masculino $(0,9 \%)$ não utiliza redes sociais.

Esse elevado número do uso do celular é também um resultado da indústria cultural que tem grande impacto no consumo atualmente. Silva (2007) traz que "a disseminação do uso dos telefones celulares, que passaram a constituir parte importante do cotidiano de um número crescente de indivíduos, em todas as partes do planeta" (p. 2).

A mesma autora comenta sobre o fato de a ciência querer entender e compreender a cultura de uso dos celulares com o consumo.

O consumo e o papel das novas tecnologias, e inclusive o dos telefones celulares, têm atraído a atenção do campo científico, no sentido de que constituem um foro privilegiado para a compreensão das relações entre cultura e consumo na contemporaneidade (SILVA, 2007, p.4).

Bauman (2001) também afirma que:

corpo esguio e adequação ao movimento, roupa leve e tênis, telefones celulares (inventados para o uso dos nômades que têm de estar 'constantemente em contato'), pertences portáteis ou descartáveis - são os principais objetos culturais da era da instantaneidade (BAUMAN, p. 149).

Autores vêm discutindo sobre esse fenômeno, como Bauman (2001) e Silva (2007), mas podemos notar, que sempre tem alguém acessando alguma rede social ou "conectado" de alguma forma no aparelho celular.

Tabela 2. Redes sociais mais acessadas em função do sexo.

\begin{tabular}{llrrr}
\hline \multirow{2}{*}{ Facebook } & & Masculino & Feminino & Total \\
& sim & $40,2 \%$ & $35,7 \%$ & $75,9 \%$ \\
\multirow{2}{*}{ Twitter } & não & $8,9 \%$ & $15,2 \%$ & $24,1 \%$ \\
\hline \multirow{2}{*}{ Google } & sim & $3,6 \%$ & $6,2 \%$ & $9,8 \%$ \\
& não & $45,5 \%$ & $44,6 \%$ & $90,2 \%$ \\
\hline \multirow{2}{*}{ Instagram } & sim & $10,7 \%$ & $16,1 \%$ & $26,8 \%$ \\
& não & $38,4 \%$ & $34,8 \%$ & $73,2 \%$ \\
\hline \multirow{2}{*}{ Linkedin } & sim & $37,5 \%$ & $42,0 \%$ & $79,5 \%$ \\
\hline
\end{tabular}




\section{REFLETIONIS}

\section{दें}

\begin{tabular}{llrrr}
\hline & não & $48,2 \%$ & $49,1 \%$ & $97,3 \%$ \\
\hline \multirow{2}{*}{ Whatsapp } & sim & $47,3 \%$ & $49,1 \%$ & $96,4 \%$ \\
& não & $1,8 \%$ & $1,8 \%$ & $3,6 \%$ \\
\hline \multirow{2}{*}{ FaceMessenger } & sim & $14,3 \%$ & $12,5 \%$ & $26,8 \%$ \\
& não & $34,8 \%$ & $38,4 \%$ & $73,2 \%$ \\
\hline \multirow{2}{*}{ Youtube } & sim & $34,8 \%$ & $35,7 \%$ & $70,5 \%$ \\
& não & $14,3 \%$ & $15,2 \%$ & $29,5 \%$ \\
\hline \multirow{2}{*}{ Não utiliza } & sim & $1,8 \%$ & $0,0 \%$ & $1,8 \%$ \\
& não & $47,3 \%$ & $50,9 \%$ & $98,2 \%$ \\
\hline
\end{tabular}

Fonte: Questionário uso de redes sociais. (SANTOS, 2018)

Sobre as redes sociais mais utilizadas em função do sexo, as mais mencionadas são: whatsApp 96,4\% , instagram 79,5\%, facebook $75,9 \%$ e youtube $70,5 \%$ e ao pesquisar estudos sobre essas redes sociais, encontramos maior número de estudos relacionados a whatsapp, instagram e facebook.

Tabela 3. Frequência de uso das redes sociais em função do sexo.

\begin{tabular}{lccccccccc}
\hline & \multicolumn{9}{c}{ Sexo } \\
\cline { 2 - 9 } Frequência & \multicolumn{9}{c}{ Masculino } \\
\cline { 2 - 9 } & Média & Mínimo & Máximo & $\begin{array}{l}\text { Desvio } \\
\text { Padrão }\end{array}$ & Média & Mínimo & Máximo & $\begin{array}{l}\text { Desvio } \\
\text { Padrão }\end{array}$ \\
\hline Dias/semana & 2,96 & 2,00 & 4,00 &, 27 & 3,00 & 3,00 & 3,00 &, 00 \\
Horas/dia & 3,31 & 1,00 & 6,00 & 1,25 & 3,04 & 1,00 & 6,00 & 1,19 \\
\hline
\end{tabular}

Fonte: Questionário uso de redes sociais (SANTOS, 2018)

Na tabela acima, consta um dado inesperado, pois o WhatsApp se enquadra como rede social e as pessoas estão cada vez mais ligadas a esse aplicativo. Porém, na pesquisa constatou-se que eles utilizam as redes sociais em média 3 dias por semana, em ambos os sexos e pelo que é observado, costumam estar conectados a um número maior de dias.

A tabela 4 apresenta a média total das respostas dos fatores do SATAQ-3 dos participantes. A média da pontuação total foi de 75,27 para o sexo masculino e 73,74 para o sexo feminino. Já em relação aos fatores, os que obtiveram maior pontuação foram os fatores 1 (internalização geral dos padrões estabelecidos), seguido do fator 4 (mídia como fonte de informações sobre aparência) para ambos os sexos, o que indica que esses fatores possuem maior influência sobre as participantes. 


\section{REFLCTIONIS}

REVISTA ELETRÔNICA DE GRADUAÇÃO E PÓS-GRADUAÇÃO EM EDUCAÇÃO

Tabela 4. Média da pontuação total e dos fatores do SATAQ-3

\begin{tabular}{|c|c|c|c|c|c|c|c|c|}
\hline & \multicolumn{8}{|c|}{ Sexo } \\
\hline & \multicolumn{4}{|c|}{ masculino } & \multicolumn{4}{|c|}{ feminino } \\
\hline & Média & Mínimo & Máximo & $\begin{array}{l}\text { Desvio } \\
\text { Padrão }\end{array}$ & Média & Mínimo & Máximo & $\begin{array}{l}\text { Desvio } \\
\text { Padrão }\end{array}$ \\
\hline Internalização geral & 21,56 & 9,00 & 39,00 & 8,04 & 22,44 & 9,00 & 33,00 & 6,20 \\
\hline Internalização atlética & 14,20 & 5,00 & 23,00 & 4,73 & 12,77 & 5,00 & 25,00 & 4,50 \\
\hline Pressão corpo perfeito & 17,05 & 7,00 & 32,00 & 7,25 & 16,30 & 7,00 & 31,00 & 6,98 \\
\hline Mídia & 22,45 & 9,00 & 45,00 & 7,96 & 22,23 & 9,00 & 38,00 & 6,79 \\
\hline Escore Total & 75,27 & 32,00 & 124,00 & 22,27 & 73,74 & 36,00 & 109,00 & 18,43 \\
\hline
\end{tabular}

O estudo de Alvarenga et al. (2010) foi realizado com universitários dos cursos: enfermagem, psicologia, fisioterapia, farmácia, fonoaudiologia ou biomedicina, todos são da área da saúde (mas o curso de Educação Física não foi incluído) em diferentes regiões do Brasil. Os autores utilizaram na sua pesquisa o questionário SATAQ-3 e o fator 1 (internalização geral) foi o que teve uma pontuação maior. Podemos notar, que neste estudo esse fator também teve uma maior pontuação nos universitários dos cursos de educação física, por mais que o estudo de Alvarenga et al. seja em regiões diferentes do Brasil, não há uma grande variação das redes sociais e na mídia pelo Brasil, isso pode ser um aspecto que faz com que os resultados das pesquisas sejam similares.

Para analisar se existe associação entre as variáveis IMC, frequência do uso de redes sociais (dias/semana e horas/dia), pontuação total do questionário de atitudes sociais relacionadas ao uso de redes sociais, fatores e pontuação total do SATAQ-3, na totalidade da amostra, foi realizado teste de correlação de Pearson. Os dados estão representados na tabela a seguir.

Tabela 5. Correlação entre as variáveis do estudo no total da amostra

\begin{tabular}{|c|c|c|c|c|c|c|c|c|c|}
\hline & & $\begin{array}{l}\text { RS/dias/ } \\
\text { semana }\end{array}$ & $\begin{array}{l}\text { RS/horas } \\
\text { /dia }\end{array}$ & $\begin{array}{c}\text { Escore } \\
\text { Total } \\
\text { QRS }\end{array}$ & $\begin{array}{c}\text { Internaliz. } \\
\text { geral }\end{array}$ & $\begin{array}{c}\text { Internaliz. } \\
\text { atlética }\end{array}$ & $\begin{array}{c}\text { Pressão } \\
\text { corpo } \\
\text { perfeito }\end{array}$ & Mídia & $\begin{array}{c}\text { Escore } \\
\text { Total } \\
\text { SATAQ-3 }\end{array}$ \\
\hline \multirow{3}{*}{ IMC } & Pearson &,- 025 & ,081 & 137 & ,073 &, 129 & $277^{* *}$ &,- 078 &, 124 \\
\hline & Sig & ,796 & ,398 & ,151 & ,444 & , 176 & ,003 & ,416 & ,194 \\
\hline & $\mathrm{N}$ & 112 & 112 & 112 & 112 & 112 & 112 & 112 & 112 \\
\hline \multirow{2}{*}{$\begin{array}{l}\text { RS/dias } \\
\text { /semana }\end{array}$} & Pearson & 1 & ,013 & ,063 &,- 040 &,- 134 &,$- 186^{*}$ &,- 028 &,- 120 \\
\hline & Sig. & & ,890 & ,513 & ,676 & , 159 &, 050 & ,770 & 209 \\
\hline
\end{tabular}




\begin{tabular}{|c|c|c|c|c|c|c|c|c|}
\hline & $\mathrm{N}$ & 112 & 112 & 112 & 112 & 112 & 112 & 112 \\
\hline \multirow{3}{*}{ RS/horas/dia } & Pearson & 1 & ,025 &,- 040 &,- 025 &,- 023 & $199^{*}$ & 044 \\
\hline & Sig & & ,792 & ,672 & ,791 & ,813 & ,036 & ,644 \\
\hline & $\mathrm{N}$ & & 112 & 112 & 112 & 112 & 112 & 112 \\
\hline \multirow{3}{*}{$\begin{array}{l}\text { Escore Total } \\
\text { QRS }\end{array}$} & Pearson & & 1 &, $423^{* *}$ &, $388^{* *}$ &, $390^{* *}$ & ,050 &, $392^{* *}$ \\
\hline & Sig. & & &, 000 &, 000 & ,000 & 603 & ,000 \\
\hline & $\mathrm{N}$ & & & 112 & 112 & 112 & 112 & 112 \\
\hline \multirow{3}{*}{$\begin{array}{l}\text { Internalização } \\
\text { geral }\end{array}$} & Pearson & & & 1 &, $592^{* *}$ & $654^{* *}$ & $440^{* *}$ &, $874^{* *}$ \\
\hline & Sig. & & & & ,000 & ,000 & ,000 & ,000 \\
\hline & $\mathrm{N}$ & & & & 112 & 112 & 112 & 112 \\
\hline \multirow{3}{*}{$\begin{array}{l}\text { Internalização } \\
\text { atlética }\end{array}$} & Pearson & & & & 1 & $484^{* *}$ &, $213^{*}$ &, $683^{* *}$ \\
\hline & Sig. & & & & &, 000 &, 024 & ,000 \\
\hline & $\mathrm{N}$ & & & & & 112 & 112 & 112 \\
\hline \multirow{3}{*}{$\begin{array}{l}\text { Pressão corpo } \\
\text { perfeito }\end{array}$} & Pearson & & & & & 1 & $361^{\text {** }}$ &, $820^{* *}$ \\
\hline & Sig. & & & & & &, 000 & ,000 \\
\hline & $\mathrm{N}$ & & & & & & 112 & 112 \\
\hline \multirow{3}{*}{ Mídia } & Pearson & & & & & & &, $691^{* *}$ \\
\hline & Sig & & & & & & & ,000 \\
\hline & $\mathrm{N}$ & & & & & & & 112 \\
\hline
\end{tabular}

Fonte: Questionário SATAQ-3 (SANTOS, 2018)

IMC (Índice de Massa Corporal); RS/dias/semana (frequência do uso de redes sociais, dias por semana); RS/horas/dia (frequência do uso de redes sociais, horas por dia); Escore Total QRS (Escore total do questionário de atitudes socioculturais em relação ao corpo/imagem corporal e a mídia); Internalização geral (Fator 1 do SATAQ-3); Internalização Atlética (Fator 2 do SATAQ-3); Pressão corpo perfeito (Fator 3 do SATAQ-3, pressão pelo corpo perfeito); Mìdia (Fator 4 do SATAQ-3, mídia como fonte de informação); Escore Total do SATAQ-3.

*. Correlação significativa para $\mathrm{p}<0,05$. **. Correlação significativa para $\mathrm{p}<0,01$.

Observa-se que na tabela 5 houve associação entre as variáveis IMC e pressão pelo corpo perfeito, sendo uma correlação significativa, positiva, mas é uma associação fraca pelo fato de o Pearson ser de, 277 , ou seja, de $27 \%$. Isso significa que as pessoas com IMC mais alto pontuaram mais no quesito pressão pelo corpo perfeito.

Outra associação se expressa na correlação entre o uso das redes sociais e a pressão pelo corpo perfeito, que teve uma significância negativa, mas a associação é muito fraca. $\mathrm{O}$ resultado pode ser considerado inesperado, pois quem pontuou menos usando as redes sociais/dias/semana, teve uma maior pontuação acerca da pressão pelo corpo perfeito. 
Os resultados também indicam associação entre o uso das redes sociais/horas por dia e a mídia, apresentando uma correlação positiva e fraca, ou seja, quanto mais horas por dia o sujeito acessa as redes sociais, mas ele se apropria da mídia como fonte de informação.

No escore total do questionário sobre atitudes socioculturais em relação ao corpo/imagem corporal e o uso de redes sociais teve uma significância positiva em vários fatores do SATAQ-3 como: internalização geral dos padrões atuais, internalização atlética, pressão para o corpo perfeito, que também apresentou correlação significativa entre o escore total do SATAQ-3. Podemos inferir, então, que a pontuação maior apresentada no questionário quanto ao uso de redes sociais e atitudes sociais em relação ao corpo, apresentou também pontuação maior no SATAQ-3, o qual avalia a influência da mídia na percepção da imagem corporal.

Nos últimos dados dessa tabela, podemos ver que os fatores do SATAQ-3 tiveram uma associação com o escore total do SATAQ-3 como, por exemplo, a mídia como fonte de informação teve $69 \%$ da pontuação total do SATAQ-3. A pressão pelo corpo perfeito apresentou 82\%, a internalização atlética 68\%, e o maior resultado foi a internalização geral, que apresentou correlação de $87 \%$ em relação à pontuação total do SATAQ-3.

\section{CONSIDERAÇÕES FINAIS}

O objetivo geral dessa pesquisa foi investigar a relação entre o uso das redes sociais, a influência da mídia e a imagem corporal de acadêmicos dos cursos de Educação Física, de ambos os sexos. Fazendo uma correlação da mídia, vemos que ela é uma grande influenciadora tanto na internalização geral dos padrões atuais, internalização atlética como também na pressão para o corpo perfeito.

Como objetivos específicos foram analisados: o uso das redes sociais por universitários, sendo que os resultados mostraram que quase $100 \%$ dos participantes usam as redes sociais, tendo apenas 1 sujeito que corresponde a 0,9\%, que não utiliza tais recursos. Em relação ao uso das redes sociais em função do sexo, ambos os sexos as utilizam, sendo quase praticamente a mesma quantidade, fazendo uma média entre dias/semana com horas/por dia

Outro objetivo específico foi investigar a influência da mídia na imagem corporal dos sujeitos; também foi averiguado se há uma relação do uso das redes sociais com a 


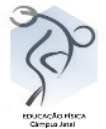

influência da mídia sobre a imagem corporal. Os resultados mostraram que quanto mais horas por dia o sujeito acessa as redes sociais, mas ela se apropria da mídia como fonte de informação. E sobre verificar se há uma influência por parte da mídia, em ambos os sexos de forma igualitária, verificamos que as diferenças são mínimas, o que nos leva a concluir nesse aspecto que a influência da mídia é de forma igualitária em ambos os sexos.

Podemos apontar nesse trabalho como limitações e dificuldades os seguintes fatos: a falta de interesse dos sujeitos para responder os questionários, sendo assim, atentamos que foram aplicados 128 questionários e 16 não foram respondidos por completo, impedindo a utilização de todos os questionários.

Esse trabalho pode contribuir para uma visão de desconstrução desse padrão de corpo disseminado pela mídia, ao ser lido ou estudado pode se notar conceitos da imagem corporal e como a mídia se utiliza desse conceito tornando um corpo padrão e disseminando na cultura como corpo ideal. Também pode-se notar o grande tempo que é gasto nas redes sociais, alertando para a influência da divulgação de um padrão estético corporal veiculado e apresentado de forma constante nessas redes.

\section{REFERÊNCIAS}

ALVARENGA, M. S. et al. Influências da mídia em universitárias brasileiras de diferentes regiões. J Bras Psiquiatr, v.2, n.59, p.111-118, 2010.

AMARAL, A. C. S. Adaptação Transcultural do Sociocultural Attitudes Towars Appearance Questionnaire - 3 (SATAQ-3) para a população brasileira. Juiz de Fora: UFJF, 2011. Dissertação (Mestrado em Educação Física) - Faculdade de Educação Física, Universidade Federal de Juiz de Fora, 2011.

ANDRIEU, B. Le dictionnaire du corps em sciences humaines e sociales. Paris: CNRS Editions, 2006.

BARROS, Daniela Dias. Estudo da imagem corporal da mulher: corpo (ir)real x corpo ideal. Campinas: UNICAMP, 2001. Dissertação (Mestrado em Educação Física) - Faculdade de Educação Física, Universidade Estadual de Campinas, 2001.

BAUMAN, Zygmunt. Modernidade Líquida. Rio de Janeiro: Jorge Zahar Ed., 2001. 


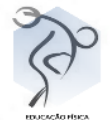

CORREIA, Célia Maria Couto. Corpo, jovens e prática de musculação: um estudo em frequentadores de academia na região do Grande Porto. Porto, Portugal: UP, 2006. Dissertação (Mestrado em Ciências do Desporto) - Faculdade de Desporto, Universidade do Porto, 2006.

DUTRA, Carlos Antonio Furtado. O que é mídia? Para que serve? [s.1]. 2011. Disponível em: https://www.webartigos.com/artigos/o-que-e-midia-para-que-serve/57042/. Acesso em: 30/10/2018.

FOUCAULT, Michel. Vigiar e punir: nascimento da prisão. Petrópolis: Vozes, 1987.

GIDDENS, Anthony. A estética da mercadoria. São Paulo: Editora UNESP, 1998.

GONÇALVES, Carolina de Oliveira; CAMPANA, Ângela Nogueira; TAVARES, Maria da Consolação. Influência da atividade física na imagem corporal: uma revisão bibliográfica. Motricidade, v. 8, n.2, p.70-82, 2012.

JACOB, Helena. Redes sociais, mulheres e corpo: um estudo da linguagem fitness na rede social Instagram. Revista Communicare Dossiê Feminismo, São Paulo, v. 14, n.1, 2014, p. 89-105.

PATROCÍNIO, J. B. A influência da mídia na academia: reflexos no cotidiano de praticantes de exercícios físicos. UNESC, 2012. Monografia (Bacharel em Educação física) Universidade do Extremo Sul Catarinense, 2012.

PIVA, J. Satisfação com a imagem corporal de mulheres que frequentam academias de ginástica no município de Jataí GO. Jataí: UFG, 2014. Trabalho de Final de Curso (Bacharelado em Educação Física) - Regional Jataí, Universidade Federal de Goiás, 2013.

PRIMO, Alex. O que há de social nas mídias sociais? Reflexões a partir da teoria atorrede. Contemporânea | comunicação e cultura - v.10 - n.03 - set-dez 2012 - p. 618-641, Porto alegre.

SCHILDER, Paul. A imagem do corpo: as energias construtivas da psique. 3.ed. São Paulo: Martins Fontes, 1999.

SANTOS, Mariany Silva. Uso das redes sociais, imagem corporal e influência da mídia em acadêmicos dos cursos de educação física. Jataí: UFG, 2018. Trabalho de Final de Curso (Licenciatura em Educação Física) - Regional Jataí, Universidade Federal de Goiás, 2018.

SILVA, Sandra Rúbia da. "Eu não vivo sem celular": sociabilidade, consumo, corporalidade e novas práticas nas culturas urbanas. Intexto, Porto Alegre: UFRGS, v. 2, n. 17, p. 1-17, julho/dezembro 2007. 


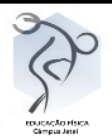

TAVARES, L.B.; BRASILEIRO; M. C. E. O espelho de Narciso: o corpo belo representado por adolescentes. In: Anais da III Jornada Internacional e I Conferência Brasileira Sore Representações Sociais, Textos completos, Rio de janeiro, 2003.

VIEIRA, Camilla Araújo Lopes; BOSI, Maria Lúcia Magalhães. Corpos em confecção: considerações sobre os dispositivos científicos e midiáticos em revistas de beleza feminina. Physis, Revista de Saúde Coletiva, Rio de Janeiro, p. 843-861, 2013. 